\title{
Virtual Reality Simulators in the Process Industry: A Review of Existing Systems and the Way Towards ETS
}

\author{
Jaroslav Cibulka ${ }^{1}$ Peyman Mirtaheri ${ }^{1}$ Salman Nazir ${ }^{2}$ Davide Manca ${ }^{3}$ Tiina M. Komulainen ${ }^{1}$ * \\ ${ }^{1}$ Department of Electronics Engineering, Oslo and Akershus University College of Applied Sciences (HiOA), Oslo, \\ Norway, tiina.komulainen@ hioa.no \\ ${ }^{2}$ Department of Maritime Technology and Innovation, University College of Southeast Norway (USN), Vestfold, \\ Norway, salman.nazir@usn.no \\ ${ }^{3}$ Department of CMIC, Politecnico di Milano, Milano, Italy, davide.manca@polimi.it
}

\begin{abstract}
Simulator training with Virtual Reality Simulators deeply engages the operators and improves the learning outcome. The available commercial 3D and Virtual Reality Simulator products range from generic models for laptops to specialized projection rooms with a great variety of different audiovisual, haptic, and sensory effects. However, current virtual reality simulators do not take into account the physical and psychological strain involved in field operators' work in real process plants. Collaborative training using Extreme Environments Training Simulators could enhance the learning process and provide a more realistic perception of the time and effort needed to carry out demanding operations in Extreme Environments. We suggest developing the following features for an optimal ETS experience and safe learning environment: immersive 3D virtual environments, mixed-reality features, automated assessment, and a monitoring system for the physiological and psychological condition of the trainees.
\end{abstract}

Keywords: training simulators, extreme environments, condition monitoring, performance assessment

\section{Introduction}

\subsection{Training simulators for process operators}

Dynamic process simulators have been used since the 1980s for control room operator training (Cameron, 2002; Nazir and Manca, 2014). In Norway, the government requires simulators to be used in operator training (Petroleum Safety Authority Norway, 2012). The benefits of operator training simulators are well documented (Ayral and Jonge, 2013; Cheltout et al., 2007; Fiske, 2007; Komulainen et al., 2012; Nazir et al., 2015; Sneesby, 2008). Typically, simulator training is organized with one instructor for a team of 2-5 control room operators. The simulation scenarios include for example shut-downs, start-ups, abnormal situations, and new procedures (Komulainen and Sannerud, 2014). In these scenarios, the simulator instructor plays the role of field operator and performs all the necessary actions instead of the field operator using the instructor computer. Operator training with high-fidelity control room simulators represents the most effective transfer of knowledge and skills: there is a strong correlation/overlap with reality and the simulation situation is almost identical to reality. Thus, simulator training effectively increases trainees' learning outcome. (Kluge et al., 2014; Spetalen and Sannerud, 2013; Tuomi-Gröhn and Engeström, 2003)

One of the aims of Virtual Reality (VR) is to evoke photo-realistic and immersive feelings and emotions that ensure the user is deeply engaged and involved in the simulation scenario. There is a close relationship between physical perception and learning capability (Bergouignan et al., 2014), (Medical Xpress, 2014). The physical manifestation of feelings enables us to store new information and improve our ability to memorize and remember. It has been proven that emotions are linked to memory processes and thus improve both learning and training (Neuroscience News, 2015), (Tendler and Wagner, 2015). The more intense the emotion, the stronger the record saved in the memory. Furthermore, stress emotions stimulate memory and the learning retention rate. Hence, VR simulators are considered an effective training tool. It has been experimentally demonstrated that VR training is more effective than conventional lectures with figures and videos (Nazir et al., 2013). Trainees memorize hands-on practice, even virtual, better than learning in classrooms by means of slides or videos (Nazir et al., 2015). Field operators can use VR simulators to train routine operations, procedures, abnormal conditions, start-ups, shut-downs, and emergency situations.

A combination of Operator Training Simulators (OTS) and Virtual Reality Simulators is used to train communication skills and team work between control 
room operators and field operators (Colombo et al., 2014; Manca et al., 2013; Nazir et al., 2014). Control room operators use a dynamic process simulator (OTS) that is connected to the Virtual Reality Simulator used by the field operators. The Virtual Reality Simulator is an immersive environment where the work site is represented in 3D with stereoscopic vision and spatial sounds (Manca et al., 2013).

\subsection{Extreme environment training simulators (ETS)}

Current VR simulators do not take into account the physical strain and effort involved in field operators' work in real processing plants. The environment and wearing protective gear increase the field operator's physical workload, and to some extent impair his /her perception (Manca et al., 2016; Nazir et al., 2015). Collaborative training using an Extreme Environment Training Simulator (ETS) can enhance the learning process and can give a more realistic perception of the time and effort required to carry out demanding operations in extreme environments.

\subsection{Research questions}

This paper surveys and discusses recent use of 3D and VR simulators for operator training in the process industry and team training between control room operators (CROP) and field operators (FOP). We propose the following research questions:

What kind of Virtual Reality Simulators are available to the chemical process industry? Which features are included in the Virtual Reality Simulators? Which features should be developed in order to provide physically and psychologically realistic operator training in Extreme Environments?

\subsection{Research methodology and scope}

The literature search included companies that provide 3D/VR simulators for the chemical process industry. Other industries were outside of the scope of the search. The literature study is mainly based on the product datasheets available on the companies' websites.

\section{Review of current 3D and virtual reality simulators}

In the following, we review the main features of nine different 3D/Virtual Reality Simulators that are available to the chemical process industry. A summary of this review is presented in Table .

The companies and their 3D/VR products included in this study are:

- EON Reality: I3TE - Immersive 3D Operator Training Simulator (EON Reality, 2015; World Oil, 2015)

- GSE Systems: Activ3Di (GSE Systems, 2013; GSE Systems, 2014)
- Illogic: VR Star (Illogic, 2016)

- Kairos 3D: Gilgamesh (Kairos3D, 2016)

- MMI Engineering: QUARTS - Quantitative Real Time Hazard Simulator (MMI Engineering)

- Schneider Electric: SimSci-EYESIM (Schneider Electric, 2015; Schneider Electric Software, 2015)

- Siemens: COMOS Walkinside ITS (Siemens AG, 2013; Siemens AG, 2016)

- Simtronics: Virtual Field Operator (VFO) (Simtronics, 2016)

- Simulation Solutions: 3D Virtual Reality Outside Operator (Simulation Solutions Inc., 2016)

\subsection{VR projection tool and audiovisual immersiveness}

The visual features of the virtual reality plant are projected to the user by means of a computer screen, a pair of 3D glasses, a head-mounted-display (HMD) or a VR projection room. The virtual reality audio can be provided by computer speakers, a stereoscopic headset or the audio system in a VR projection room. An example of the projection room is shown in Figure 1.

Computer screens with loudspeakers are inexpensive and computationally less demanding than other alternatives. Five of the companies included in this study use 3D glasses or a head-mounted-display such as the Oculus Rift (Oculus VR, 2015).

The VR projection room is a quite expensive solution, although there are many different alternatives on how to implement such rooms, also known as Cave, Dome or Cube (Muhanna, 2015). Only one of the companies included in this study uses a VR projection room -EON Reality with its EON Icube(EON Reality, 2016).

\subsection{VR avatar control}

The movements of the trainee in the virtual reality environment, e.g. the avatar, can be controlled using a keyboard, a mouse, a gamepad, voice commands, or a gesture tracking device (Leap Motion, 2016).

Gesture-tracking devices used in Virtual Reality solutions include Microsoft Kinect, Leap Motion's Orion (Leap Motion, 2016) and VICON Bonita B10.

\subsection{Features: Immersiveness}

An immersive system evokes photo-realistic and immersed feelings/emotions of being deeply engaged and involved. A good immersive effect can be achieved by using affordable, high-quality head-mounteddisplays combined with directional and surround sound effects. Immersive Virtual Reality training is more effective than conventional training.

Simulators that use computer screens for visualization, loudspeakers for sound, and a keyboard or mouse for avatar control are not Immersive Virtual Reality simulators, but 3D simulators. 
Simulators that use more advanced hardware tools can be classified as VR simulators, the degree of immersivity depends on the different visual/audio/haptic effects projected to the user (EON Reality, 2015).

\subsection{Features: View and multi-user capabilities}

All of the 3D and VR simulators only have a first person (1p) view, but two of the products have a third person view (3p).

Most of the Virtual Reality simulators can have multiple users in the same scenario, which is very realistic for many scenarios including emergency situation training.

\subsection{Features: 3D objects and graphic effects}

All of the VR products allow the trainee to interact with the equipment and to see the status / position of the equipment in the VR plant, such as valve opening and measurement values. Four of the VR producers have implemented seamless motion effect for the equipment changing from one state to another. This feature increases the transfer outcome between the simulated situation and the workplace situation, and improves the learning effect.

Many of the VR simulators allow the user to see through the equipment in the VR environment, for example the liquid level in the tanks. Two of the VR simulators provide visualization of fire and smoke, and use CFD-like simulations to predict the spread of gases and liquids, see Figure 2.

\subsection{Features: Augmented Virtual Reality (AVR)}

Another feature that some of the advanced VR simulators have adopted recently is Augmented Virtual Reality. As the name suggests, additional information is imposed in the virtual environment to improve the user's learning. Figure 3 represents this feature.

\subsection{Features:immersive 4D sensory effects}

The EON reality I3TE reports enhanced 4D immersive sensory effects, including tactile feedback, odors, vibration, and wind simulation (EON Reality, 2015). The vibration is generated by a motor under the floor, and the wind is generated by directional fans.

\subsection{Features: Learning management system}

Some of the 3D/ VR simulators include a learning management system (LMS) that gives an automatic score to the trainees after the simulation scenario. The learning outcome can thus be quantitatively assessed. A VR simulator with LMS can be used for (periodic) verification of the operators' competencies. This feature enables the user/trainee to continuously improve his/her performance. Generally, the assessment of performance is made by an expert assessor, which can easily be biased by his/her experience and knowledge. Therefore, objective performance measures ensure more robust, consistent, and unbiased assessments of performance.

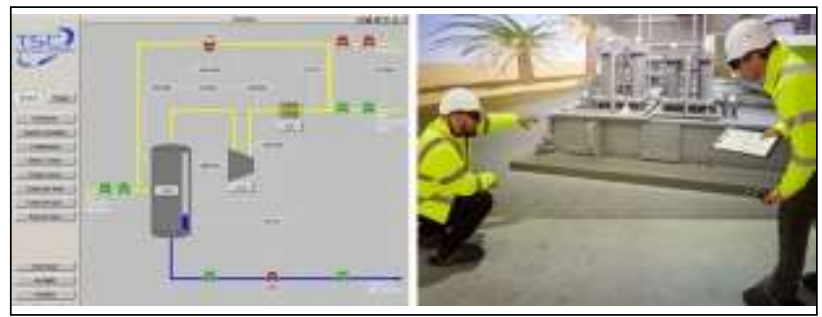

Figure 1: Process simulator by TSC Simulation is connected to the virtual reality environment I3TE by EON reality.

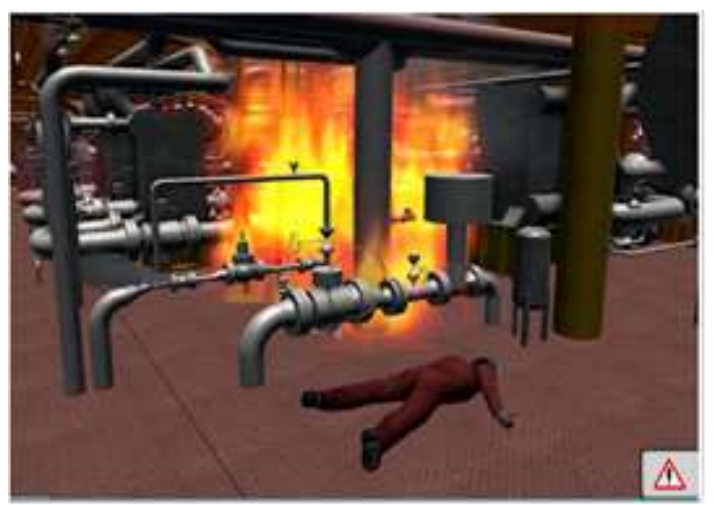

Figure 2: Emergency situation, Visualization of fire in COMOS Walkinside simulator (Siemens AG, 2013).

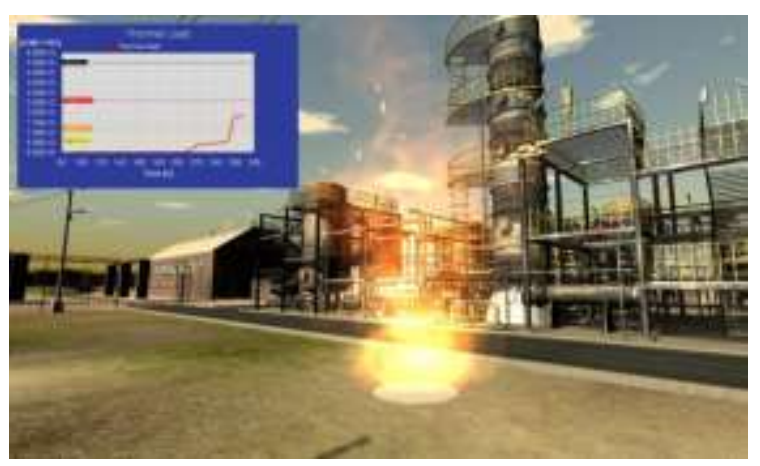

Figure 3: A simulation of an accident where AVR is used to impose additional information (graph on left top corner) (Nazir and Manca, 2014). 


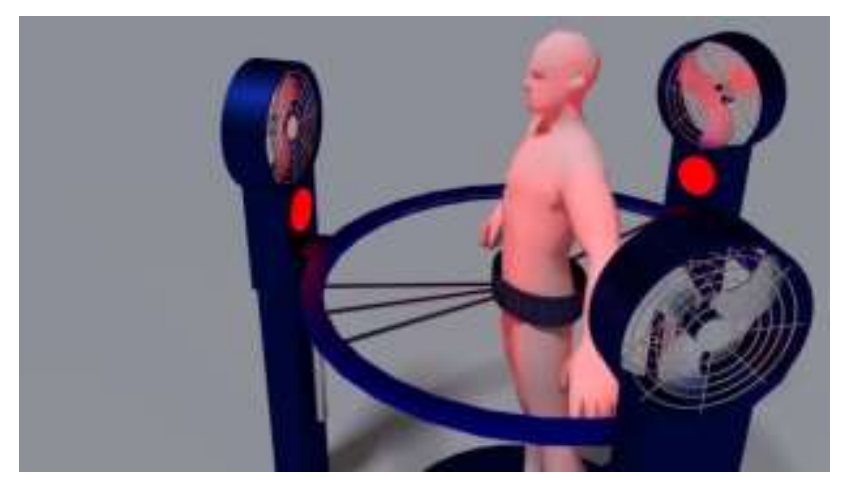

Figure 4: Omnidirectional treadmill with embedded IR lamps and fans.

\section{Extreme environment training simulator (ETS)}

The aim of the ETS is to improve the immersiveness of VR simulators by including all of the physical strain and effort involved in field operators' work in real processing plants. The environment and wearing protective gear increase the physical workload of the field operator, and to some extent impair his/her perception (Manca et al., 2016; Nazir et al., 2015). In the following subchapters, we summarize the current VR features required by the ETS simulator, and propose features that need to be developed together with the required safety and health measures

\subsection{Existing features}

The existing features in VR simulators include:

- Audio effects: noise, equipment-specific sound patterns, process-specific sound patterns, weatherspecific sounds such as wind

- Visual effects: light, weather patterns, spread of gases and liquids. Fire, smoke, assembly/disassembly of equipment, see- through $(\mathrm{X}-\mathrm{sec})$ view

-Visual effects in Augmented Reality: Thermal/Radiation/Toxic exposure

- Sensory/ olfactory effects: odors (low H2S).

- Sensory/ haptic effects: wind (directional fans), vibration feedback (motor under floor)

- Sensory/ thermal effects: heat

- Collision detection (optical motion capture)

- Learning management system

\subsection{Features to be developed}

In addition to the existing VR simulator features, the following features should be developed in order to provide fully immersive training sessions (Manca et al., 2016). A greater degree of immersion is expected to improve Key Performance Indicators (KPIs) and Distributed Situation Awareness (DSA).

- Environmental factors that need to be implemented in the ETS in a safe manner: temperature, pressure, gravity, elevation/height.
- Environmental factors requiring protective gear: harsh conditions, low oxygen, high exposure to radiation, acids/bases/salts, water deficiency, polluting/toxic substances.

We propose the following equipment be used in ETS sessions:

- Audiovisual equipment: Smartphone VR headsets represent an attractive and low-cost alternative to the self-contained PC HMDs. Utilizing smartphones is a versatile, mobile and untethered VR solution. For VR rendering, it employs the smartphone's display, GPU, CPU, memory, sensors, and other embedded features. The embedded sensors, i.e. MEMS gyroscope and accelerometers, are used for head tracking and data logging.

- Physical equipment representing the distance and elevation changes in the processing plants: the Steward platform or the Omnidirectional treadmill (Virtuix, 2016) presented in Figure 4. Enables the trainee to walk, run, crouch, jump, and freely rotate. It has embedded motion detection sensors, including foot tracking in the low-friction baseplate. The trainee is safely secured in the harness as part of the revolving ring.

- Weight compensation representing gravity and elevation: Adjustable weight compensation such as the Counterbalance weight system in the Cyberith Virtualizer (Virtual Reality Reporter, 2015).

- Wearables representing the work tools, protective gear including suit, shoes, gloves glasses, masks, and oxygen bottles.

- Haptic gloves providing feedback from the interactive process equipment and work tools in the VR environment, for example CyberTouch II (CyberGlove, 2016).

- Heat could be simulated to the trainees: Infrared lamps could be used as presented in Figure 4 (Cyberith, 2016) or overalls/garments with embedded HVAC features.

- Wind could be simulated to the trainees: Directional fans as presented in Figure 4 (Cyberith, 2016).

- Pressure could be simulated to the trainees: Overalls/garments with embedded HVAC features.

- Augmented reality could be used to visually compensate for the health related factors such as low oxygen, water deficiency, polluting/toxic substances. These could be implemented as visual effects like blurry vision, black spots, flickering.

- The learning outcome should be assessed using automatic assessment system with EE performance indicators as described in (Nazir et al., 2015).

\subsection{Safety and health measures for EE training}

The trainee is safely secured in the revolving harness that surrounds the treadmill (Virtuix, 2016) presented in 
Figure 4. The cables from the VR headset and other equipment are secured by an overhead boom.

Due to the hard physical strain of the Extreme Training Simulation, the health status of the trainees should be monitored. We propose monitoring vital signs such as:

- Body core temperature (headphones)

- Heart rate (pulse watch)

- Respiration rate

In addition to parameters such as:

- Eye movement tracker (headset)

- Balance (accelerometer and magnetometer)

- $\quad$ EMG (strain on the legs)

- Pulseoximeter (oxygen saturation)

- Stress indicators such as Cortisol or algorithms to calculate the stress level

Normal values for the core temperature vary between 36.7 and 37.5 (Sund-Levander et al., 2002). Several non-invasive thermopile sensors can measure the temperature of various parts of the body and predict the core (intragastric) body temperature, and thus indicate the heat stress in industrial applications (Graveling et al., 2009). These sensors can be integrated into the headphones in order to measure the temperature within the ear canal, or be placed in the headbands or integrated into the clothing. The heart rate and respiration can be measured by current chest band devices. The maximum heart rate is usually calculated as 220 minus age. There are several studies that have reported heart rate variability in correlation with stress, see for example (Thayer et al., 2012). Regarding the stress level, the respiration rate may increase rapidly during stress, which causes hyperventilation. During hyperventilation,, oxygen saturation increases while the level of arterial $\mathrm{CO}_{2}$ decreases. In general, a decrease of $\mathrm{CO}_{2}$ in the blood will consequently decrease the diameter of the blood vessels, including the main blood supply to the brain. This reduction in the blood supply to the brain leads to symptoms such as lightheadedness and tingling in the fingers. Severe hyperventilation can lead to loss of consciousness.

Monitoring these parameters continuously during training will provide feedback on the physiological, and, indirectly, psychological state of the trainees, which is important for their safety but also for optimizing the learning effect.

\section{Conclusions}

The available commercial 3D and Virtual Reality Simulator products range from generic models for laptops to specialized projection rooms with a great variety of different audiovisual, haptic and sensory effects. Over the past few years, VR simulators have capitalized on the technology advancement in an optimal manner, such that newly integrated features have improved their effectiveness/usefulness.

However, Extreme Environment effects such as temperature, pressure, gravity, elevation/height, harsh conditions, low oxygen, high exposure to radiation, acids/bases/salts, water shortage, polluting/toxic substances should be developed in order to provide realistic training sessions. Monitoring physiological and psychological conditions based on the trainees' vital signs and stress-related factors should be included in order to ensure a safe training environment. In combination with the performance assessment indicators, these parameters may also be applied as markers for an optimal simulator experience.

This article paves the way for research on the evolving topic of Extreme Environment Training Simulators.

\section{Acknowledgements}

The authors acknowledge the European Union's Erasmus+ program for funding the teacher mobility that led to the research collaboration on Extreme Environment Training Simulators. The Norwegian Labour and Welfare Administration is gratefully acknowledged for funding the first author.

\section{References}

T. Ayral and P. D. Jonge. Operator training simulators for brownfield process units offer many benefits. Hydrocarbon Processing, 92(2):45-47, 2013.

L. Bergouignan, L. Nyberg, and H. H. Ehrsson. Out-ofbody-induced hippocampal amnesia. Proceedings of the National Academy of Sciences, 111(12):44214426, 20124. doi: http://dx.doi.org/10.1073/pnas.1318801111

D. Cameron, C. Clausen, and W. Morton. Dynamic simulators for operator training. In B. Braunschweig, Gani, R., editor, Software Architectures and Tools for Computer Aided Process Engineering. Volume 11, pages 393-431, 2002

Z. Cheltout, R. Coupier, and M. Valleur. Capture the longterm benefits of operator training simulators. Hydrocarbon Processing, 86(4):111-116, 2007.

S. Colombo, S. Nazir, and D. Manca. Immersive virtual reality for decision making in process industry: experiment results. SPE Economics \& Management, 2014.

CyberGlove. CyberTouch II. Available via http://www.cyberglovesystems.com/cybertouch2/ [accessed 2.6.2016, 2016]

Cyberith. Cyberith Virtualizer. Available via http://cyberith.com/ [accessed 1.6.2016, 2016].

EON Reality. Immersive 3D Training Environment (I3TE) - Enhanced Virtual Reality Based Training for Plant Operators/Engineers. Available via http://www.eonreality.com/?wpfb_dl=54 [accessed 5.2.2016, 2015]

EON Reality. I3TE - Immersive 3D Training Environment. Available

via 
http://www.eonreality.com/applications/i3te/ [accessed 5.2.2016, 2016].

T. Fiske. Benefits of dynamic simulation for operator training. Hydrocarbon Processing, 86(12):17-17, 2007.

R. Graveling, L. MacCalman, H. Cowie, J. Crawford, and P. George. Reliable industrial measurement of body temperature: The use of infrared thermometry of tympanic temperature to determine core body temperature in industrial conditions. Institute of Occupational Medicine, 2009.

GSE Systems. GSE Systems Introduces 3Di-TouchWall, Affordable Alternative to CAVE Simulation for Immersive $3 D$ Training. Available via http://www.gses.com/news/gse-systems-introduces3di-touchwall-affordable-alternative-to-cavesimulation-for-immersive-3d-training [accessed 31.05.2016, 2013].

GSE Systems. GSE Activ3Di Trailer. Available via https://vimeo.com/89492818 [accessed 31.05.2016, 2014].

Illogic. VR Star virtual reality platform. Available via http://www.illogic.us/\#!/vr-star-virtual-realityplatform [accessed 17.2.2016, 2016].

Kairos3D. Kairos $3 D$ interactive $3 D$ solutions. Available via http://www.kairos3d.it/solutions/gilgamesh/ [accessed 31.05.2016, 2016].

A. Kluge, S. Nazir, and D. Manca. Advanced Applications in Process Control and Training Needs of Field and Control Room Operators. IIE Transactions on Occupational Ergonomics and Human Factors, 2(34):121-136, $2014 . \quad$ doi: 10.1080/21577323.2014.920437

T. M. Komulainen and R. Sannerud. Survey on simulator training in Norwegian oil \& gas industry, in $\mathrm{HIOA}$ rapport vol. 4, ed. Oslo: Oslo and Akershus University College, p. 27, 2014.

T. M. Komulainen, R. Sannerud, H. Nordhus, and B. Nordsteien. Economic benefits of training simulators. (in English), World oil, (12):R61-R65 2012.

Leap Motion. Leap Motion Introduces Orion, Its NextGeneration Hand Tracking Product for Developers in $V R / A R$. Available via https://www.leapmotion.com/news/leap-motionintroduces-orion-its-next-generation-hand-trackingproduct-for-developers-in-vr-ar [accessed 29.2.2016, 2016].

D. Manca, S. Brambilla, and S. Colombo. Bridging between Virtual Reality and accident simulation for training of process-industry operators. Advances in Engineering Software, 55:1-9, 2013. doi: http://dx.doi.org/10.1016/j.advengsoft.2012.09.002

D. Manca, S. Nazir, T. M. Komulainen, and K. I. Øvergård. How Extreme Environments Can Impact the Training of Industrial Operators. Chemical Engineering Transactions, 52:6, 2016.

Medical Xpress. $(2014,10.3 .2014)$ Outside the body our memories fail us. Medical Xpress. Available: http://medicalxpress.com/news/2014-03-bodymemories.html
MMI Engineering. MMI Engineering - QUARTS Hazard Simulation. Available via http://www.atticusdigital.com/mmi-engineeringquarts-hazard-simulation [accessed 16.2.2016,

M. A. Muhanna. Virtual reality and the CAVE: Taxonomy, interaction challenges and research directions. Journal of King Saud University - Computer and Information Sciences, 27(3):344-361, 2015. doi: http://dx.doi.org/10.1016/j.jksuci.2014.03.023

S. Nazir and D. Manca. How a plant simulator can improve industrial safety. Process Safety Progress, 2014. doi: 10.1002/prs. 11714

S. Nazir, S. Colombo, and D. Manca. Testing and analyzing different training methods for industrial operators: An experimental approach. Computer Aided Chemical Engineering, 32:667-672, 2013.

S. Nazir, A. Kluge, and D. Manca. Automation in Process Industry: Cure or Curse? How can Training Improve Operator's Performance. Computer Aided Chemical Engineering, 33:889-894, 2014. doi: http://dx.doi.org/10.1016/B978-0-444-634566.50149-6

S. Nazir, L. J. Sorensen, K. I. Øvergård, and D. Manca. Impact of training methods on Distributed Situation Awareness of industrial operators. Safety Science, 73:136-145, $2015 . \quad$ doi: http://dx.doi.org/10.1016/j.ssci.2014.11.015

S. Nazir, D. Manca, T. M. Komulainen, and K. I. Øvergård. Training Simulator for Extreme Environments. In Proceedings of the Creating Sustainable Workenvironments NES2015, Lillehammer, Norwegian Society of Ergonomics and Human Factors 2015.

Neuroscience News. (2015, 7.8.2015) Emotions Directly Influence Learning and Memory Processes. Neuroscience News, . Available: http://neurosciencenews.com/learning-memoryemotion-limbic-system-2393/

Oculus VR. Start Building: Start turning your dreams into virtual realities. Available via https://developer.oculus.com/ [accessed 19.1.2016, 2015].

(2012). Veiledning til aktivitetsforskriften Til § 23 Trening og фvelser. Available: http://www.ptil.no/aktivitetsforskriften/category383. html\#_Toc345589379

Schneider Electric, SimSci - Solutions for Enhancing Refinery Performance and Profitability, ed: Schneider Electric, 2015.

Schneider Electric Software. EYESIM Immersive Training System. Available via http://software.schneiderelectric.com/pdf/datasheet/eyesim-immersivetraining-system/ [accessed 5.2.2016, 2015].

Siemens AG. Powerful 3D visualization with COMOS Walkinside, 2013.

Siemens AG. Training for Safety and Profit - Virtual 3D Immersive Training Simulator Makes Case for Stronger ROI. Available via https://webservices.siemens.com/adtree/newsdb/detai 1/html.aspx ?language $=$ en $\&$ filename $=$ TOTAL $\% 20 \mathrm{EP}$ 
_COMOS_2014_en.xml\&frame $=1 \&$ view $=0 \&$ design $=1 \&$ print $=1$ [accessed 31.05.2016, 2016].

Simtronics. Virtual Field Operator (VFO) - Interactive 3D Virtual Training Environment. Available via http://www.simtronics.com/site/vfo.htm\#.V01frK1f1 aQ [accessed 31.05.2016, 2016].

Simulation Solutions Inc. Simulator Software - Generic Training Simulators. Available via http://simulationsolutions.com/simulator-software.html [accessed, 2016].

M. Sneesby. Operator training simulator: myths and misgivings. Hydrocarbon Processing, 87(10):125127, 2008.

H. Spetalen and R. Sannerud. Erfaringer med bruk av simulering som transferstrategi. (in Norwegian), Nordic Journal of Vocational Education and Training, 3:17, 2013.

M. Sund-Levander, C. Forsberg, and L. K. Wahren. Normal oral, rectal, tympanic and axillary body temperature in adult men and women: a systematic literature review. Scandinavian Journal of Caring Sciences, 16(2):122-128, 2002. doi: 10.1046/j.14716712.2002.00069.x

A. Tendler and S. Wagner. Different types of theta rhythmicity are induced by social and fearful stimuli in a network associated with social memory. eLife, 4, 2015. doi: http://dx.doi.org/10.7554/eLife.03614

J. F. Thayer, F. Åhs, M. Fredrikson, J. J. Sollers Iii, and T. D. Wager. A meta-analysis of heart rate variability and neuroimaging studies: Implications for heart rate variability as a marker of stress and health. Neuroscience \& Biobehavioral Reviews, 36(2):747756 , 2012. doi: http://dx.doi.org/10.1016/j.neubiorev.2011.11.009

T. Tuomi-Gröhn and Y. Engeström. In Between school and work: new perspectives on transfer and boundarycrossing. Amsterdam: Pergamon, pp. X, 333 s., 2003.

Virtual Reality Reporter. (2015, 1.7.2015) Cyberith Virtualizer: Immersive VR Gaming Equipment. Virtual Reality Reporter. Available: https://virtualrealityreporter.com/cyberith-virtualizer/

Virtuix. Virtuix Omni. Available via http://www.virtuix.com/ [accessed 1.6.2016, 2016].

World Oil. (2015, 5.5.2015) ExxonMobil awards license to EON Reality for Immersive 3D Operator Training Simulator technology. World Oil. Available: http://www.worldoil.com/news/2015/5/05/exxonmob il-awards-license-to-eon-reality-for-immersive-3doperator-training-simulator-technology 
Table 1. Comparison of VR simulator products.

\begin{tabular}{|c|c|c|c|c|c|c|c|c|c|}
\hline $\begin{array}{c}\text { VR } \\
\text { company }\end{array}$ & $\begin{array}{l}\text { EON } \\
\text { Reality }\end{array}$ & $\begin{array}{l}\text { GSE } \\
\text { Systems }\end{array}$ & Illogic & Kairos 3D & \begin{tabular}{|l|} 
MMI \\
Engineerin \\
$\mathrm{g}$
\end{tabular} & $\begin{array}{l}\text { Schneider } \\
\text { Electric }\end{array}$ & Siemens & Simtronics & \begin{tabular}{|l|} 
Simulation \\
Solutions, \\
Inc. \\
\end{tabular} \\
\hline $\begin{array}{c}\text { VR } \\
\text { Product }\end{array}$ & $\begin{array}{c}\text { I3TE - } \\
\text { Immersive } \\
\text { 3D } \\
\text { Operator } \\
\text { Training } \\
\text { Simulator } \\
\end{array}$ & Activ3Di & VR Star & Gilgamesh & \begin{tabular}{|c} 
Quantitati \\
ve Real \\
Time \\
Hazard \\
Simulator- \\
QUARTS \\
\end{tabular} & $\begin{array}{l}\text { SimSci- } \\
\text { EYESIM }\end{array}$ & $\begin{array}{c}\text { COMOS } \\
\text { Walkinsid } \\
\text { e ITS }\end{array}$ & $\begin{array}{l}\text { Virtual } \\
\text { Field } \\
\text { Operator } \\
\text { (VFO) }\end{array}$ & $\begin{array}{c}\text { 3D Virtual } \\
\text { Reality } \\
\text { Outside } \\
\text { Operator }\end{array}$ \\
\hline $\begin{array}{c}\text { Learning } \\
\text { Manageme } \\
\text { nt System }\end{array}$ & $\checkmark$ & $\checkmark$ & N/A & $\checkmark$ & N/A & $\checkmark$ & $\checkmark$ & N/A & $\checkmark$ \\
\hline $\begin{array}{c}\text { Immersive } \\
\text { VR }\end{array}$ & $\checkmark$ & $x$ & $\checkmark$ & $x$ & $\checkmark$ & $\checkmark$ & $\checkmark$ & $x$ & $x$ \\
\hline $\begin{array}{c}\mathrm{VR} \\
\text { projection }\end{array}$ & $\begin{array}{c}\text { room (EON } \\
\text { Icube), 3d } \\
\text { glasses, } \\
\text { HMD } \\
\text { (Oculus } \\
\text { Rift, } \\
\text { Samsung } \\
\text { Gear VR) }\end{array}$ & $x$ & $\begin{array}{c}\text { monitor, } \\
\text { 3d glasses, } \\
\text { HMD } \\
\text { (Oculus } \\
\text { Rift) }\end{array}$ & $x$ & $\begin{array}{c}\text { monitor, } \\
\text { HMD } \\
\text { (Oculus } \\
\text { Rift) }\end{array}$ & $\begin{array}{c}3 \mathrm{~d} \\
\text { glasses/st } \\
\text { ereos copic } \\
\text { headset, } \\
\text { 3D } \\
\text { projection, } \\
\text { 3D HDTV }\end{array}$ & $\begin{array}{c}\text { monitor, } \\
\text { 3d glasses, } \\
\text { HMD } \\
\text { (Oculus } \\
\text { Rift) }\end{array}$ & $x$ & $x$ \\
\hline $\begin{array}{l}\text { Avatar } \\
\text { control }\end{array}$ & \begin{tabular}{|} 
gesturing \\
(VICON \\
Bonita \\
B10), voice \\
commands \\
, gamepad
\end{tabular} & $\begin{array}{c}\text { keyboard+ } \\
\text { mouse, } \\
\text { gamepad }\end{array}$ & gamepad & gamepad & $\begin{array}{c}\text { keyboard+ } \\
\text { mouse, } \\
\text { gamepad }\end{array}$ & $\begin{array}{l}\text { gloves, } \\
\text { gesturing, } \\
\text { gamepad }\end{array}$ & $\begin{array}{c}\text { gesturing } \\
\text { (via } \\
\text { Kinect), } \\
\text { keyboard+ } \\
\text { mouse, } \\
\text { gamepad }\end{array}$ & $\begin{array}{c}\text { keyboard+ } \\
\text { mouse, } \\
\text { gamepad }\end{array}$ & mouse \\
\hline Viewpoint & $1 p$ & $1 \mathrm{p}$ & $1 p$ & $1 p$ & $1 p$ & $1 p, 3 p$ & $1 p, 3 p$ & $1 \mathrm{p}$ & $1 p$ \\
\hline $\begin{array}{c}\text { Multi-user } \\
\text { training }\end{array}$ & $\checkmark$ & $\checkmark$ & $\checkmark$ & $\checkmark$ & N/A & $\checkmark$ & $\checkmark$ & N/A & $\checkmark$ \\
\hline $\begin{array}{l}\text { Interactive } \\
3 \mathrm{D} \text { objects }\end{array}$ & $\begin{array}{l}\text { valves, } \\
\text { buttons, } \\
\text { gauges, } \\
\text { etc. }\end{array}$ & $\checkmark$ & $\begin{array}{l}\text { valves, } \\
\text { gauges, } \\
\text { tanks, } \\
\text { engines, } \\
\text { etc. }\end{array}$ & $\checkmark$ & $\checkmark$ & $\checkmark$ & $\begin{array}{c}\text { live-action } \\
\text { items }\end{array}$ & N/A & $\begin{array}{c}\text { valves, } \\
\text { pumps, } \\
\text { controllers }\end{array}$ \\
\hline $\begin{array}{c}4 \mathrm{D} \\
\text { Immersive } \\
\text { effects }\end{array}$ & $\begin{array}{c}\text { 3D sound, } \\
\text { tactile } \\
\text { feedback, } \\
\text { odors } \\
\left(\mathrm{H}_{2} \mathrm{~S}\right), \\
\text { vibration } \\
\text { (under } \\
\text { floor), 3D } \\
\text { wind } \\
\text { (fans) } \\
\end{array}$ & N/A & N/A & $\begin{array}{c}\text { visual } \\
\text { effects, } \\
\text { item- } \\
\text { specific } \\
\text { sounds/no } \\
\text { ises }\end{array}$ & N/A & N/A & $\begin{array}{l}\text { 3D sound, } \\
\text { odors, } \\
\text { vibration }\end{array}$ & N/A & $x$ \\
\hline $\begin{array}{l}\text { Graphic } \\
\text { effects }\end{array}$ & N/A & $\begin{array}{c}\text { see } \\
\text { through/in } \\
\text { equipment, } \\
\text { X-sec view }\end{array}$ & N/A & $\begin{array}{c}\text { see } \\
\text { through/in } \\
\text { equipment, } \\
\text { X-sec view }\end{array}$ & $\begin{array}{c}\text { Fire/Smoke } \\
\text { - CFD, } \\
\text { adjustable } \\
\text { model }\end{array}$ & $\begin{array}{c}\text { see } \\
\text { through/in } \\
\text { equipment, } \\
\text { X-sec view }\end{array}$ & $\begin{array}{c}\text { Fire/Smoke } \\
\text { - CFD }\end{array}$ & N/A & $x$ \\
\hline $\begin{array}{l}\text { Enhanced } \\
\text { features }\end{array}$ & N/A & N/A & $\begin{array}{c}\text { weather } \\
\text { conditions }\end{array}$ & $\mid \begin{array}{c}\text { as sembly/ } \\
\text { dis as s emb1 } \\
\text { y of } \\
\text { equipment }\end{array}$ & $\begin{array}{c}\text { thermal } \\
\text { radiation } \\
\text { exposure, } \\
\text { fall risk, } \\
\text { injury/fatal } \\
\text { ity level }\end{array}$ & \begin{tabular}{|c|} 
PPE \\
selection, \\
compatibili \\
ty with \\
mobile \\
devices,
\end{tabular} & $\begin{array}{c}\text { radiation/t } \\
\text { oxic } \\
\text { exposure, } \\
\text { RFID } \\
\text { chips (FOP } \\
\text { location) }\end{array}$ & N/A & $x$ \\
\hline
\end{tabular}

